\title{
The formation of a conceptual-categorical apparatus of the theory of education management as an indicator of the methodology development
}

\author{
T. V.Sych \\ Luhansk Taras Shevchenko National University, Ukraine, Starobelsk \\ Corresponding author. E - mail: tatynasych@gmail.com
}

Paper received 28.04.18; Accepted for publication 05.05.18.

\section{http://doi.org/10.31174/SEND-PP2018-165VI69-09}

Abstract. The article analyzes the results of the research of terminology of national theory of education management in the works of national scholars. It is given the characteristic of the process of formation of the conceptual-categorical apparatus of education management national theory in certain periods in comparison with the peculiarities of the methodology development of the education management problems research.

Keywords: education management, conceptual-categorical apparatus, terminology research, development of the theory, development of methodology.

Introduction. Each scientific branch passes from the empirical stage to the theoretical in its genesis. One of the indicators of the transition of scientific knowledge to a qualitatively new theoretical level is the formation of its conceptual system. The using of scientific concepts is a prerequisite for constructing and studying theoretical models, understanding the processes of education management in dynamics and perspective, allows define the subject of research more clearly and build a consistent concept of its study. The solution in the study of conceptual problems becomes an inalienable condition for the formation of innovative theories of management. That is why the problem of systematization of the conceptual apparatus took shape as the most important methodological problem. Detection and study of the laws of this process is of great importance for understanding the mechanisms of development and functioning of scientific knowledge. There are various factors that influence the process of forming a conceptual-categorical apparatus in the scientific field. However, there is no doubt about the existence of such patterns as the dependence of the formation of the conceptual-categorical apparatus on the level of development of the methodology of research in a scientific field. Brief review of publications on the topic. The development of the terminology apparatus in the field of education management was undertaken by M. Galaguzova, G. Yelnikov, V. Kryzhko, A. Moiseev, M. Murashko, V. Pikelna, V. Polonskyi, M. Potashnik, M. Cherpinskyi, E. Khrykov, V. Shapovalova and others. The problem of the uniqueness of terms in pedagogical research is highlighted in the works of V. Kraievskyi, N. Korshunova, E. Khrykovata and others. The works by O. Adamenko, E. Khrykova, V. Shapovalova, $\mathrm{N}$. Misko are devoted to the analysis of terminology of the theory of education management.

The aim of the article: to consider the process of formation of a conceptual-categorical system of the national theory of education management in comparison with the development of the methodology of studies of education management problems.

Materials and methods. The article analyzes the results of the research of terminology of the education management national theory in works by O. Adamenko, E. Khrykov, N. Misko. As a result of the consideration of more than 500 terms, branched out in philosophical, pedagogical dictionaries, scientific and methodical literature, educational manuals on the management of educational institutions, scientific publications and dissertation works, the process of formation of a thesaurus of national theory of education management in comparison with the development of methodology of studies on education management problems is analyzed in the relevant periods.

The results and their discussion. Formation of the concept is a complex and lengthy process of scientific research. The latest achievements of science and social practice are accumulated and concentrated in the concepts. Theoretical systems are created in the process of scientific activity, they consist of abstractions - a categorical apparatus, systems of concepts, which reflect the subject of this field of knowledge. Investigating the problems of the conceptual-terminology apparatus of pedagogy and the theory of education management, M. Galaguzova stresses the methodological aspect of this problem, connected primarily with the improvement of the system of concepts and terms, its ordering, systematization, clarification of the content and scope of concepts [197, p. 20]. In the national science, there are practically no works devoted to the study of the peculiarities of formation of the conceptual-terminology apparatus of the theory of education management. An exception is the dissertation research by Adamenko O.V. "The development of the theory of general school management in Ukraine in the second half of the twentieth century" [1], which presents the results of the analysis of the semantic spectrum of titles, orientation and content of publications and theses of the Ukrainian authors of the second half of the twentieth century, devoted to the problems of managing a general secondary school, the list of terms, which scholars and practical education workers used in the names of their publications and dissertations on the problems of managing secondary schools in the second half of the twentieth century. However, due to the fact that the focus of the study was only on the management of a comprehensive school, the study does not cover the entire conceptual-categorical system of the national theory of education management.

The scientific thesaurus of the national management theory was thoroughly analysed in the dissertation research by $\mathrm{N}$. Misko in terms of the following criteria: the relation of the concept to the group of notions of the national theory of education management, the long-term existence of the concepts; emergence of new concepts; ethnocultural genesis concept. She notes that 493 different terms and concepts were used in the research period (the last quarter of the $\mathrm{XX}$ century - the beginning of the XXI century) in the scientific publications, dissertations and other scientific-pedagogical literature [3]. However, our analysis of the nomenclature of terms given in the dissertation allows us to conclude that the 
list is incomplete. Outstanding attention was paid to such modern concepts as educational strategy, strategic planning, fundraising, staggering, risk management, competence, human resources, managerial decision, quality of education, educational service, a customer of educational service, accreditation, licensing, management situation, management ethics, etc. Consequently, the modern scientific thesaurus of the national management theory far exceeds 500 concepts. However, the study contains valuable results, which can be used to trace the stages of formation, to determine the factors of development of the concept and terminology apparatus of the national theory of management, features and methodology of its formation.

The first criterion allows determining the focus of scientific research on solving certain problems of the national theory of education management, as well as their influence on the formation of scientific thesaurus in the investigated period. The analysis was carried out in accordance with six thematic directions, in which identified scientist relies on the research Adamenko O.V. These are concepts that characterize the development of theoretical management problems related to the subjects of education management and their activities; related to types of educational institutions and their subdivisions; related to the control and analytical activity; related to the planning of the work of the educational institution and the concepts related to personnel work.

The author determined that the most concepts characterize the development of theoretical management problems $(36 \%$ of the total number of concepts). The number of concepts related to the subjects of management of education and their activities is $17 \%$. $13 \%$ of the total number of concepts are related to the types of educational institutions and their units, as well as with control and analytical activities. The smallest percentage was received by groups of concepts related to the planning of work of an educational institution (11\%) and personnel work (10\%). In the paper, the increasing tendency of the quantitative composition of scientific thesaurus of national theory of education management from the 80's of the twentieth century was revealed(from 84 concepts in 7680 years to 113 concepts in the 80 's.), the peak reached in the 90's of the twentieth century (164 concepts), and a certain decline in 2001-2016 compared with the 90's (up to 132 concepts in 2001-2016). This fact gave the scientist the reason to assume that since the 80 's of the twentieth century, in connection with the onset of a deep crisis of the Soviet system, with the gradual revision of the authoritarian educational education paradigm, which was prevalent in the Soviet era, beginning in the second half of the 80's XX century, the processes of democratization of management, the quantitative composition of scientific thesaurus of national theory of education management is gradually enriched with new terms and concepts. Changes are in the quantitative composition of the scientific thesaurus of the national theory of education management in the 90's years of the twentieth century, caused by the penetration of the ideas of Western management theory, are the reflection of the process of forming a new paradigm of education management at this time. A certain decrease in the number of concepts in 2001-2016, N. Misko explains by the process of reflection and clarification of the concepts of the scientific thesaurus of national theory of education management at this historic stage of its development.

Studying the duration of the existence of the concept, the scientist singled out 25 concepts, the long-term nature of which is confirmed by their presence in the scientific publications of domestic scientists and practitioners, in dissertations and other scientific-pedagogical literature, throughout the studied period. These notions form the categorical level of a scientific thesaurus of national theory of management education, which links the science of education management with philosophy. The concepts (mainly 70-80's of the 20th century), which preserved their relevance only during certain periods, were discovered, and in subsequent periods they gradually lost their relevance and disappeared from the structure of the thesaurus. It explains the significant organizational and structural changes that have taken place at all levels of education management with the acquisition of Ukraine by state independence, democratization processes, humanization and deideologization of governance.

The study of concepts that arise at a particular historical stage and which were not used at previous historical stages, allowed the scientist to determine the level of updating the scientific thesaurus of the national theory of education management in the recearching period. So there are 28 notions in the 80 's of the twentieth century. This process reached the peak in the 90s of the twentieth century (more than 100 new notions). It is explained by the process of changing education paradigms in this period of education, from authoritarian to democratic. During this period, there are such concepts as: "management", "educational management", " management of modification", "quality management education", etc., domestic scientists begin to use terms and concepts related to competence, management style, management functions, professional qualities of managers, psychological aspects of management, etc. In our opinion, this fact shows both the further differentiation of the object of management of education and the increasing of interdisciplinary ties. At the beginning of the XXI century modifications continue due to intersystem, interdisciplinary borrowings as a part of the scientific thesaurus of the national theory of education management. This process is proved by the emergence of such terms of foreign-language origin in this period as "benchmarking", "qualimetry," "marketing," "monitoring." In total, Mrs. N. allocates 196 new concepts that make up $40 \%$ of the total number of concepts of the scientific thesaurus of the national theory of education management.

The results of the study of the ethno-cultural genesis of the concepts allowed the scientist to determine the relationship between Ukrainian and foreign language concepts, the level of foreign language borrowing. Indeed, scientific terminology has a fairly high ability to accept foreign language borrowings. Such borrowings form a common lexical fund in different languages, which contributes to the mutual understanding of specialists who speak different languages. Changes in the political system of Ukraine and its release into the international arena as an independent state are the main factors in the renewal of the lexical composition of the Ukrainian language. But the main reasons, according to D. Mazurik, are internal ones - the need to call a new concept; the desire to give a new (more clearly or shorter) name of the reality of the external world, which already has a name. An analysis of new concepts of a scientific thesaurus of national theory of education management in the last quarter of the XX century - the beginning of the XXI century, according to this indicator, shows that among the new concepts that it has been enriched over this period, $17 \%$ make up the concepts borrowed from modern European languages. The key term that defines the main direction of change in the theory and 
practice of management of educational systems, in the 90's of the twentieth century becomes the term "management". Its introduction into the scientific thesis of the national theory of education management stimulates the formation of the corresponding terminological field and reflects the strengthening of the influence of economy on the development of social institutions of society. The influx of terms-inter-system borrowing and the introduction of terms from foreign management theory characterizes the development of the scientific thesaurus of the national theory of education management in the last quarter of the XX century - beginning of the XXI century is the desire for internationalization and harmonization. Cross-system borrowing of concepts and terms, on the one hand, leads to the expansion of scientific thesaurus of national theory of education management. However, it should be noted that the increase in the terms of the scientific thesaurus of national theory of education management is not always a sign of enrichment of scientific knowledge on the management of education, since in some cases the new management terminology has such disadvantages as meaningful incorrectness, the lack of conceptual novelty and systematicity.

Beyond the attention of the researcher there was an analysis of the dynamics of the development of concepts in certain periods in the middle of each thematic group. In the graph on Fig. 1. the results of this analysis are presented, which shows four periods of development of concepts ( 1 - up to 80 years, 2 - in the 80 's, 3 - in the 90 's, 4 - since 2001 up to 2016) and the increasing number of concepts in each of the six thematic groups, expressed as a percentage of the number of these concepts in the relevant thematic group. As it is seen, the most intensive growth has come from a group of concepts that characterize the development of theoretical management problems. So the percentage distribution of this group of concepts over the years yields the following results: by the 80 th years $-14.5 \%$, in the 80 's $-22.3 \%$, in the 90 's $33 \%$, since $2001-28.5 \%$. Practically every thematic group of concepts has gained the rapid development in the 90 's. The number of concepts related to the types of educational institutions and their divisions has increased twice during this period. Constant and even growth dynamics is observed in a group of concepts related to personnel work. The given data testify to the fact that indeed, the 90 s were a turning point in the development of national theory of education management. After a long period of isolation from world scientific achievements in this field, as a result of political and social changes, the domestic scientific community gained access to foreign management theories, which had a significant impact on the development of the national theory of education management. As a result, the concept-categorical apparatus of the national theory of education management was enriched with new concepts, terms of foreign origin, and others like that.

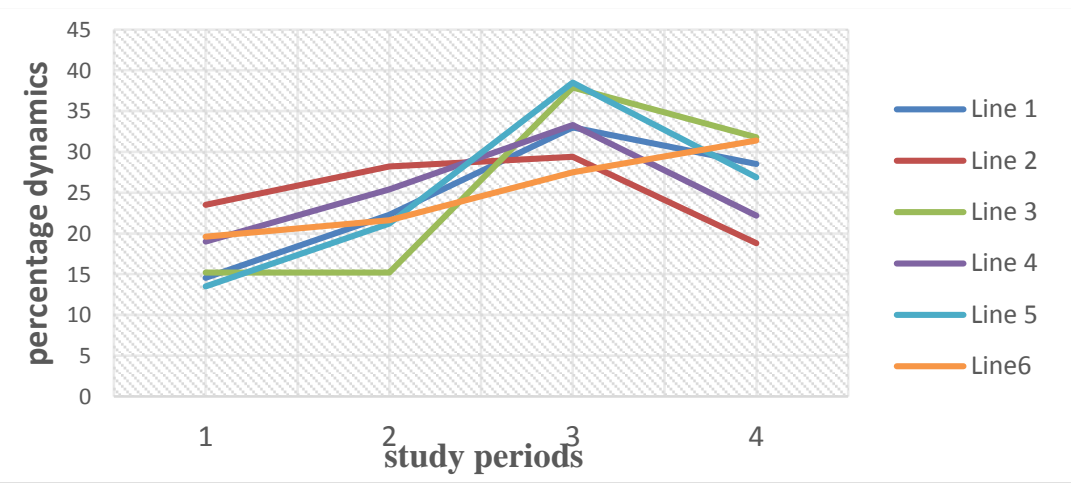

Fig. 1. Dynamics of the development of concepts in certain periods according to the thematic groups

Line 1 - concepts related to the development of theoretical management problems;

Line 2 - concepts related to the subjects of management of education and their activities;

Line 3 - concepts related to the types of educational institutions and their subdivisions;

Line 4 - concepts related to control and analytical activities;

Line 5 - concepts related to the planning of the work of an educational institution; Line 6 - concepts related to personnel work.

It was in the 1990s that new types of educational institutions were emerging, and management theory began to reflect the global trends in the democratization of management and outgoing from this position. So the movement for democratization in Europe has led to the recognition of human resources as the highest value of the organization. Basic management theories recommend strengthening the role of the human factor. The staff is considered to be one of the most important resources of the organization. Mostly, the accounting and technical functions of HR departments vary from analytical and organizational to quality engagement, recruitment and development of staff. Note that the principles of a new approach to personnel management point to the aspiration of the theorists and practitioners of the concept of human resources to emphasize the importance of personnel in modern management and to find more effective ways of their use that changes the entire system of personnel work and approaches to personnel management, activates the development of the movement for competence, promotes awareness and increasing the importance of corporate culture. All these trends are reflected in the scientific thesaurus of national theory of education management.

In her study N.Misko practically does not pay attention to such an important factor in the formation of the conceptualcategorical apparatus of the theory of education management as the development of the methodology of studies on education management issues. If we compare the development of the scientific thesaurus of the national theory of education management and the development of the methodology, one can find close interconnections. So in the national science of Soviet times, the methodology of science began to be formalized only in the 60 's -70 's. During this period, the methodology contained in the Marxist-Leninist doctrine reigned, which hindered the development of the theory of education management and its thesaurus, and so on. In the 70-80-s formed methodology of the system approach as a direction in 
science, which has a general scientific character. The main principles of the domestic concept of systemic research, the level of methodological analysis, the relations of the system approach and dialectics are determined, the search for research methods is being determined. So in the 70-80's the scientific thesaurus of the national theory of education management was replenished with the concepts that became the result of the study of the system and management functions. However, the study of education management problems in that period is based on the description of the leading management experience, as a consequence, the definition of concepts carried out by scientists is more intuitive, based on the inductive method. Popper, however, opposed the use of inductive methods in empirical sciences, pointing to the socalled "induction problem", which questioned the truth of universal statements based on experience [4]. When applying the deductive method, the conclusion should be based solely on the evidence presented above and should not contain new information about the subject under study. Induction, on the other hand, operates with a set of incomplete facts, and, on the basis of them, makes a conclusion which is certain, without giving any guarantees as to its truth. Deduction is more applicable in mathematics and natural sciences, which use mathematical methods. In the 90-s years in the social sciences, in pedagogy, management education, etc., methods and theories of definitive sciences, which previously did not perform methodological functions in these branches of science, are beginning to be used. The power of the deductive way of developing the theory of education management becomes effective. With the development of cybernetics, the application of mathematical methods (methods of mathematical statistics, modeling) is applied in studies of education management problems. When working with the conceptual apparatus of research, scientists increasingly use methods such as content analysis, semantic analysis, conceptualterminology analysis. Since this period, the number of concepts has grown rapidly across all thematic groups, most of which have come into thesaurus from western management theories and have a foreign genesis. The number of studies devoted to solving non-local problems of management, and the substantiation of the general principles of management, is increasing. In this connection, the number of concepts characterizing the theoretical management problems is growing. Since 2000 we can talk about the formation of a national general theory of management of educational systems. So in pedagogy there is a new specialty "theory and methodology of education management", which indicates the separation of the scientific branch of education management. With the
Ukraine accession into the Bologna process in 2005, the ideas of quality management penetrate into the national theory of education management. On the basis of ISO standards, national standards are developed and implemented, among which are DSTU ISO 9000: 2015 Quality Management Systems. Basic States and Glossary. These are regulatory documents developed by leading specialists in accordance with the current achievements of management and trends in the development of the theory of management, which have a methodological function and have influenced the formation of a modern thesaurus of the national theory of education management. To date, no dictionary on the theory of education management has been published in Ukraine. Terms and concepts are branched out in philosophical, pedagogical dictionaries, scientific and methodical literature, educational manuals on the management of educational institutions, scientific publications and dissertation research. In the research methodology, the clear procedure for defining and substantiating scientific concepts has not been developed. Indeed, scientists-methodologists consider the problem of uniqueness, the proof of scientific concepts. However, in the normative documents, where the procedure for awarding academic degrees and the methodological function on this issue are determined, the requirements for the substantiation of the concepts are not defined.

Conclusions. Changes in the scientific thesaurus of national theory of education management are quantitative and qualitative in nature. Its formation is not completed for today. The rapid development of the conceptual-categorical apparatus of national theory of education management begins in the 90's in connection with the acquisition of Ukraine's independence, the democratization of governance, the reform of the educational branch, the penetration of western theories into the domestic scientific space, the intensification of interdisciplinary ties and the introduction of new research methods . Consequently, its development is due to various factors, one of which is the methodology of studies on education management issues. The level of its development depends on the uniqueness of the formulations of the concepts, the validity of the introduction of new concepts, the direction of expansion of the problem field of scientific research, the consequence of which is a certain thematic direction of the concepts of scientific thesaurus. Considering this, we can review the conceptual-categorical apparatus of national theory of education management as an indicator of development of the methodology of studies on education management issues.

\section{REFERENCES}

1. Adamenko O.V. Ukrainian Pedagogical Science in the second half of the 20th Century: Monograph. - Lugansk: Alma Mater, 2005. $-704 \mathrm{p}$.

2. Galaguzova M.A. Concept-terminological problems of pedagogy and education / M.A. Galaguzova, G. N. Shtinova // Pedagogics. -1997 . - № 6. - P. $15-20$.

3. Misko N.V. Development of the national thesaurus of the theory of education management (last quarter of the XX - beginning of the XXI century): diss. candidate of pedagogical sciences: 13.00.06 / Natalia Misko. - Starobilsk, 2016. - 321 p.

4. Popper K.R. Logic and growth of scientific knowledge. Select. works /Tr. from English - Moscow: Progress, 1983. -605 pp.

Сформированность понятийно-категориального аппарата теории управления образованием как показатель развития методологии

Т. В. Сыч

Аннотация. В статье проанализированы результаты исследований терминологии отечественной теории управления образованием. Дана характеристика процессу формирования понятийно-категориального аппарата отечественной теории управления образованием в определенные периоды в сравнении с особенностями развития методологии исследований проблем управления образованием.

Ключевые слова: управление образованием, понятийно-категориальный аппарат, исследование терминологии, развитие теории, развитие методологии. 